\title{
A Framework for Measuring the Impact of Wildland-Urban Interface Fires on a Regional Economy
}




\title{
A Framework for Measuring the Impact of Wildland-Urban Interface Fires on a Regional Economy
}

\author{
David T. Butry \\ David H. Webb \\ Cheyney M. O’Fallon \\ Applied Economics Office \\ Engineering Laboratory \\ Harvey Cutler \\ Department of Economics \\ Colorado State University
}

This publication is available free of charge from:

https://doi.org/10.6028/NIST.TN.2026

February 2019

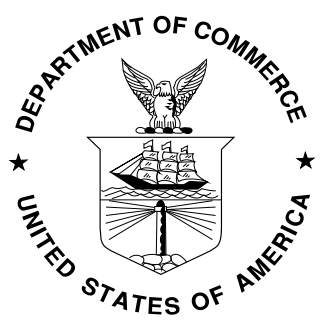

U.S. Department of Commerce Wilbur L. Ross, Jr., Secretary

National Institute of Standards and Technology Walter Copan, NIST Director and Undersecretary of Commerce for Standards and Technology 
Certain commercial entities, equipment, or materials may be identified in this document to describe an experimental procedure or concept adequately. Such identification is not intended to imply recommendation or endorsement by the National Institute of Standards and Technology, nor is it intended to imply that the entities, materials, or equipment are necessarily the best available for the purpose.

National Institute of Standards and Technology Technical Note 2026

Natl. Inst. Stand. Technol. Tech. Note 2026, 28 pages (February 2019)

CODEN: NTNOEF

This publication is available free of charge from:

https://doi.org/10.6028/NIST.TN.2026 


\begin{abstract}
This report develops an approach to evaluate the direct and indirect impacts from wildlandurban interface (WUI) fires that result in the loss of functionality of the built environment, for a regional economy. While direct losses from WUI fires are largely observable, needed is a mechanism to evaluate how these losses indirectly affect other sectors of the economy. The approach is designed to quantify the total impacts (both direct and indirect) from WUI fire due to a loss of functionality of assets (e.g., structures) directly impacted in a regional economy, and provides a mechanism to systematically quantify the interplay between direct and indirect economic impacts. The use of a computable general equilibrium (CGE) model allows for simulation of various possible economic shocks resulting from the temporary or permanent loss of the built environment. It also allows for behavioral changes of the local population due to fire risk. The output from such an approach will facilitate a better understanding of the potential vulnerabilities within a community. For example, the approach will identify thresholds of functionality that if exceeded would result in catastrophic loss. In addition, simulation of risk mitigation scenarios (allowing for a resilience in functionality) could be used to determine optimal intervention strategies. Combined with intervention cost data, cost-effective risk mitigation strategies can be identified.
\end{abstract}

\title{
Key words
}

Disaster; economics; mitigation; regional economics; resilience; risk mitigation; wildfire; wildland fire; wildland-urban interface. 


\section{Table of Contents}

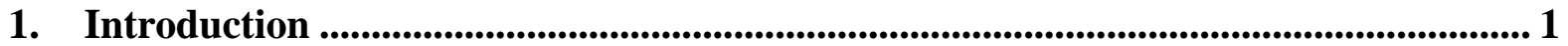

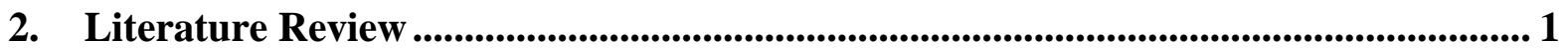

2.1. Economic Impacts of Wildfire ............................................................................ 1

2.2. Housing Price Effects from Wildfire Risk ……………........................................... 3

2.3. Regional Economic Modeling of Natural Hazards ................................................... 3

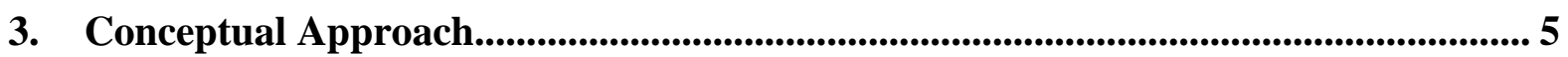

4. Computable General Equilibrium Model ............................................................................... 6

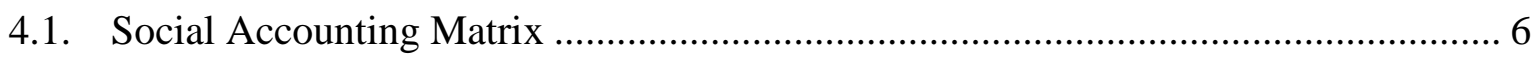

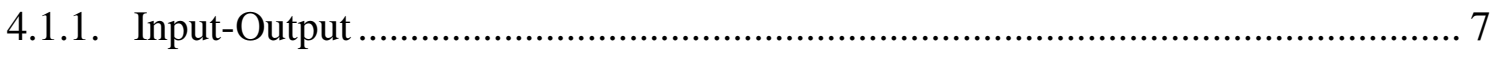

4.1.2. Household Expenditures................................................................................ 7

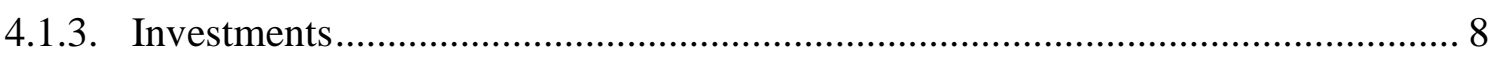

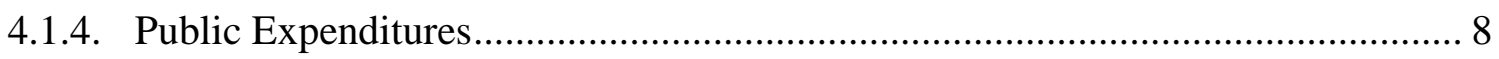

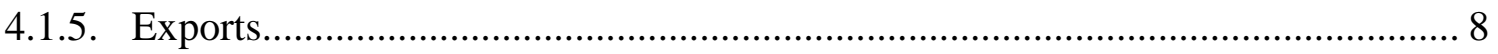

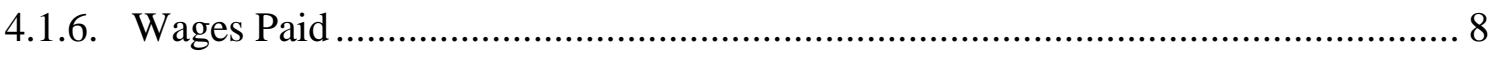

4.1.7. Capital Payments ........................................................................................ 8

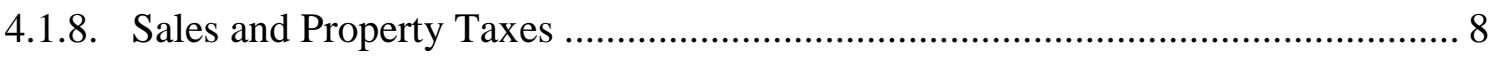

4.1.9. Import Demand............................................................................................. 9

4.1.10. Wage Transfers...................................................................................... 9

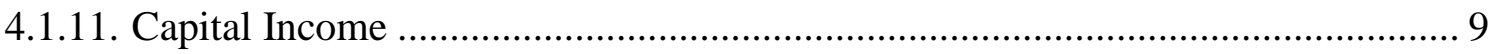

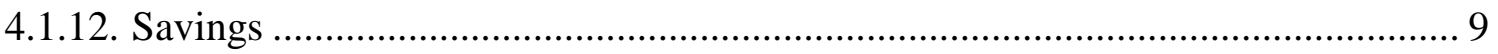

4.1.13. Sales, Property and Income Taxes ................................................................... 9

4.1.14. Social Security Payments \& Public Transfers........................................................ 9

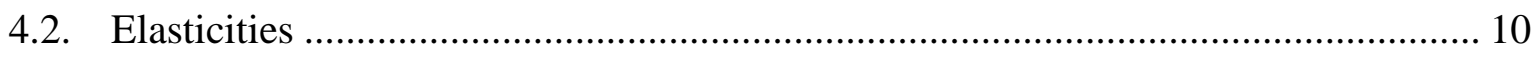

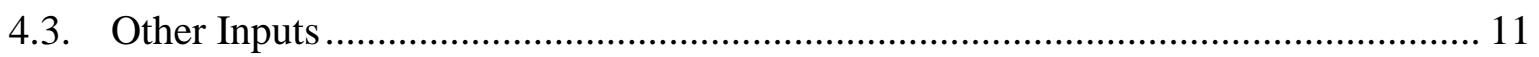

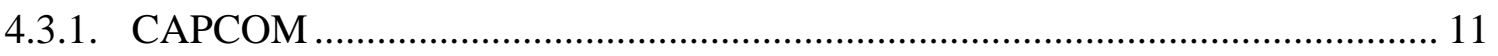

4.3.2. Labor (Employment, Working Households, and Job Core) ................................. 11

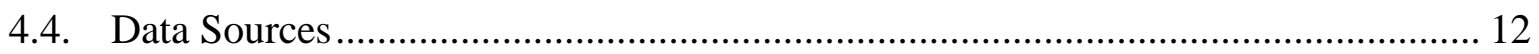

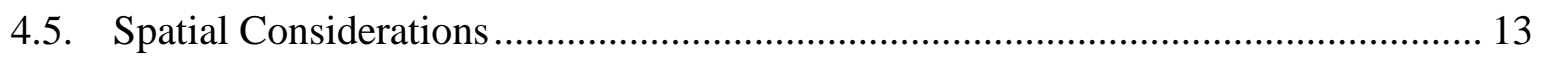

5. Simulating WUI Shocks and Mitigation in a CGE Model............................................. 13

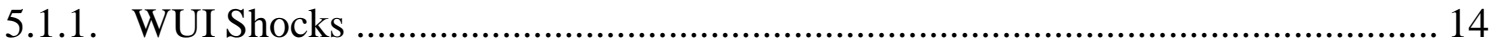

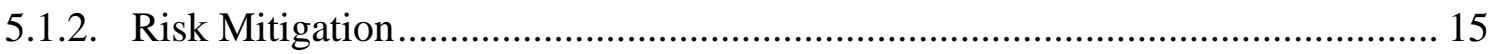

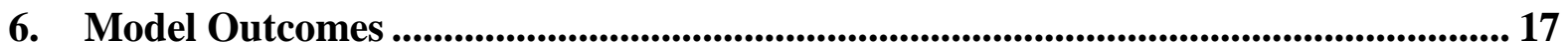

7. Loss Surfaces \& Decision-Making ........................................................................... 18 


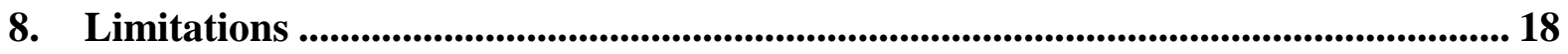

9. Conclusions........................................................................................................................ 19

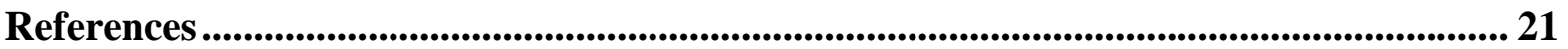

\section{List of Tables}

Table 1: SAM Segment Data Linkages ……………….................................................. 12

\section{List of Figures}

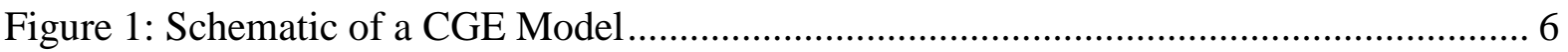

Figure 2: Conceptualization of the Social Accounting Matrix (SAM) ...................................... 7 


\section{Introduction}

Wildland and wildland-urban interface (WUI) fires have significant economic impacts on communities. Thomas et al. [1] estimated that wildfires created at least $\$ 71.1$ billion in economic burden in the U.S. in 2016. (Economic burden includes both the losses due to fire damage and the costs of intervention [e.g., suppression].) Insured property losses are large, but they represent only a part of the entire economic burden created. For example, according to Verisk, ${ }^{1,2}$ California experienced $\$ 13$ billion in insured wildfire losses in 2017, surpassing the previous 10-year total of \$5.1 billion dollars for the entire United States. However, many economic impacts remain unmeasured, particularly indirect losses (see Ref. [1] for more details).

This report develops an approach to evaluate the direct and indirect impacts from WUI fires that result in the loss of functionality of the built environment, for a regional economy. Needed is a mechanism to evaluate how direct losses induce indirect impacts across economic sectors. The approach is designed to quantify and distinguish between the total impacts from WUI fire due to a loss of functionality of assets (e.g., structures, businesses) directly impacted, and provides a mechanism to systematically quantify the interplay between direct and indirect economic impacts. For example, one objective is to determine those direct effects that have the largest spillovers in the economy. It would also provide a better understanding of the magnitude of indirect effects compared to those that are direct.

The approach makes use of a computable general equilibrium (CGE) model. A CGE model allows for simulation of various possible economic shocks resulting from the temporary or permanent loss of the built environment. It also allows for the evaluation of behavioral changes of the local population due to fire risk. The output from such an approach will facilitate a better understanding of potential vulnerabilities within a community. For example, the approach will identify thresholds of functionality that if exceeded would result in catastrophic loss. In addition, simulation of risk mitigation scenarios (providing increased resilience in functionality) could be used to determine optimal intervention strategies. Combined with intervention cost data, cost-effective risk mitigation strategies can be identified.

The remainder of the report is organized as follows: Section 2 provides a literature review; Section 3 develops the conceptual approach; Section 4 introduces the CGE model; Section 5 describes the simulation process; Section 6 presents the expected? main model output; Section 7 discusses how the model output could be used for decision-making; Section 8 describes limitations; and Section 9 discusses how this approach will be applied in future work?.

\section{Literature Review}

\subsection{Economic Impacts of Wildfire}

A few studies have examined the economic impacts resulting from wildfires. In general, they are empirical, focusing on a past individual wildfire, and tend to only include very large

\footnotetext{
${ }^{1}$ See: https://www.verisk.com/siteassets/media/campaigns/gated/underwriting/fireline-state-risk-report/california.pdf. Last accessed $09 / 11 / 2108$.

${ }^{2}$ See: https://www.verisk.com/insurance/visualize/key-findings-from-the-2017-verisk-wildfire-risk-

analysis/?utm_source=Social\&utm_medium=Twitter\&utm_campaign=VeriskSM\&utm_content=842017. Last accessed 09/11/2018.
} 
wildfires. Butry et al. [2] estimated the losses resulting from the 1998 wildfires in Florida. Out of the $\$ 600$ million to $\$ 800$ million in estimated total losses, they identified that the largest contributors were due to impacts to the regional timber market (\$300 million to \$500 million) and to the tourism and service sectors (\$138 million). In an analysis of the 2002 Haymen Fire (Colorado), Kent et al. [3] found the wildfire induced overall employment growth of $0.5 \%$ (retail sales experienced a $4 \%$ increase), but a decline in average wages by $3 \%$. Unlike in Butry et al. [2], wage growth was experienced in tourism and service related sectors, meaning other sectors of the economy experienced the loss. They also found evidence of property tax losses due to damaged structures. Also focusing on employment and wage dynamics, Davis et al. [4] examined the changes resulting from 2008 large wildfires in Trinity County, California. They found that employment in the natural resource sector increased by $30 \%$, while average wages fell by $19 \%$; whereas wage growth was experienced in the trade, transportation, and utilities sector (9\%) and leisure and hospitality sector (11\%). (They indicated that half of the \$150 million spent on suppression went towards contracted services.) However, some have found only modest impact. Keegan et al. [5] examined the Montana forest industry following the wildfires of 2000. They concluded other market forces better explained changes to the timber market, unrelated to the wildfires. Pulgiese et al. [6] found little impact from changes in timber harvests of national forests (1977 to 2010) on the employment dynamics in western US counties.

Focusing on chronic occurrences of wildfires, Nielsen-Pincus et al. [7] evaluated the impact of large wildfires on county-level employment and wage growth in western US states over the period of 2004 to 2008. Large wildfires were defined as those that resulted in federal suppression spending more than $\$ 1$ million. They found large wildfires increased employment growth by $1 \%$ and average wages by $0.8 \%$ during the quarter of the year containing the wildfire. Counties reliant on recreation-based economy experienced a $1.4 \%$ increase in employment growth; whereas, counties with large government employment saw a wage increase of $2.7 \%$. However, metropolitan counties experienced no significant change in growth, while counties dominated by service industries saw a decline in employment over $2.0 \%$.

Nielsen-Pincus et al. [8] extended their previous work (Ref. [7]) and explored the economic impacts of large wildfires in the western US states by economic sector. For counties with populations under 250 000, they found large wildfires increased total employment $(0.3 \%)$. Sectors with employment increases included natural resources and mining; trade, transportation, and utilities; information services; financial services; and federal employment. Natural resources and mining experienced the largest increase at $2.44 \%$. Sectors that lost employment included construction; manufacturing; professional and business services; education and health services; and leisure and hospitality services. Leisure and hospitality services experienced the largest loss at $-2.71 \%$. For counties with populations over 250000 , total employment shrank from wildfire by $0.04 \%$. (The employment growth estimates in Ref [8] $-0.3 \%$ and -0.04—appears to contrast with Ref [7] of $1.0 \%$.) Notable differences with smaller counties included: natural resources and mining declined; manufacturing increased; leisure and hospitality services increased; and federal employment decreased. For larger counties, trade, transportation, and utilities experienced the largest increase in employment (0.98\%), while federal employment saw the largest decline (-2.05\%). 
Duffield et al. [9] explored changes to recreational visitations to Yellowstone National Park due to wildfire occurrence over 1986 to 2011. They found the loss in visitation was $1.3 \%$ in an average fire year ( $0.3 \%$ in a median year), which translated to a $\$ 6.1$ million economic loss in visitor spending.

\subsection{Housing Price Effects from Wildfire Risk}

Housing value effects are another researched topic relating wildfire occurrence (or wildfire risk) with economic impacts. Hedonic analysis correlates home sales prices or assessment values with attributes of the homes. Several studies have evaluated the effect of wildfire risk on home sales prices, with the expectation that risk lowers sales prices, all else equal.

Loomis [10] compared housing sale prices before and after the 1996 Buffalo Creek fire (Colorado). He estimated a price decline between $13 \%$ to $15 \%$ of undamaged homes nearby the fire. Kim and Wells [11] used forest crown canopy closure (within a $0.5 \mathrm{~km}$ area around each home) as a wildfire risk measure to evaluate the effect of risk on housing prices in the Greater Flagstaff area (Arizona). Moderate crown canopy closure (40 \% to $69 \%$ ) was shown as preferred by home buyers (increased home sale prices); whereas high crown canopy closure (70 \% and higher), which posed a higher wildfire risk, was shown to decrease sale prices. Donovan et al. [12] compared housing sales prices before and after the Colorado Springs Fire Department rated the wildland fire risk of individual homes in the community. The availability of risk information resulted in a decrease of a representative home value by $13.7 \%$.

Hjerpe et al. [13], in a study of house prices in four western WUI cities (2011 to 2014), found that the sales of homes with medium forest density (34\% to $66 \%$ ) within $100 \mathrm{~m}$ was associated with lower sales prices; yet, homes with high forest density (67 \% and greater) within $500 \mathrm{~m}$ was associated with higher sales prices. The latter finding is in contrast to Kim and Wells [11]. However, Hjerpe et al. [13] are accounting for forest density within $100 \mathrm{~m}$. The implication being that vegetation nearby is valued, so long as it is not too close. Stetler et al. [14] examined home sales prices in northwest Montana from 1996 to 2007. They found that distance to the fire, time since fire, size of fire, and whether the home was within viewing distance of fire affected home sales. A home within $5 \mathrm{~km}$ of the fire was shown to have the largest average price effect at $-13.7 \%$.

Kalhor et al. [15] evaluated the impact of visible fire scars from the 2000 Cerro Grande fire (Los Alamos, New Mexico) on assessed house values in 2013. In addition, they included a measure of future wildfire risk, calculated as the crown area with high fire potential near the house. The impact of previous damage equated to a $1.7 \%$ to $4.4 \%$ decline in assessed house value, while the risk measure was found to be correlated to an increase in assessed house value by $0.3 \%$ to $0.4 \%$. The increase, which was not expected, was attributed to the crown area likely accounting for the aesthetic value of vegetation.

\subsection{Regional Economic Modeling of Natural Hazards}

Most of the wildfire literature detailed above was based on econometric methods to evaluate economic impacts. In addition to econometric-based models, the literature of modeling 
economic impacts from natural hazards includes the use of input-output (IO) and computable general equilibrium (CGE) models, as well as some hybrid approaches. The social accounting matrix method (SAM) is another option, but it is not commonly used, at least solely (Ref. [16]). ${ }^{3}$ Empirically-based econometric models use observational data to statistically test economic relationships. IO models are deterministic models, based on a set of multipliers that describe inter-industry relationship (i.e., how output flows through the economy). SAM models, like IO models, depict economic relationships, but are based on linking payments and receipts of payments between economic actors. CGE models include the use of SAMs, but also account for behavioral responses (see Section 4).

Econometrics models, while statistically rigorous, cannot differentiate between direct (e.g., losses to manufacturing output due to structure damage) and indirect losses (e.g., losses to manufacturing output due to suppliers affected by fire damage) (Ref. [16]). An advantage of IO and CGE models is the ability to simulate exogenous shocks to a local economy and consider direct and indirect effects separately. Rose and Liao [18] used a CGE model to evaluate the effect of an outage of the Portland Metropolitan Water System from an earthquake. Their simulations showed indirect effects equaled $22 \%$ of the direct losses. Carrera et al. [19] assessed economic impacts from flooding in Northern Italy using a CGE model, and found indirect losses totaled approximately $20 \%$ of the direct losses. Hallegatte [20, 21], using a hybrid input-output model to evaluate the effects of Hurricane Katrina, demonstrated that measures of direct loss are not enough to approximate indirect loss.

IO and CGE models differ in complexity and modeling assumptions. A key difference regards assumed price dynamics following a shock - CGE allows for price changes, while IO does not. IO models tend to estimate larger loss estimates than CGE partly due to the lack of price and behavioral responses (Ref. [18, 21]). Koks et al. [16] compared, for the same disaster, loss estimates produced from several hybrid IO and CGE models. They found differences up to a factor of seven across the models. While the variation was mostly related to the assumed shape of the recovery path, differences across modeling approaches were also found. Depending on the nature of the shock, allowing for price adjustments may or may not be necessary - e.g., focusing on short-term effects or on sectors of the economy that might have much effect on prices. However, an advantage of a CGE model is it is theoretically consistent with neoclassical principals.

Some similarities to the wildfire literature include the modeling of differential effects on employment and wages across industries for disasters including hurricanes and tornados (Ref. [22-25]); however, missing from the wildfire literature is a systematic measurement of indirect effects from large wildland-urban interface (WUI) fires.

The remainder of the report explores the use of a CGE model to evaluate the direct and indirect effects from economic shocks induced from large WUI fires.

\footnotetext{
${ }^{3}$ An IO model and SAM are used as a part of the CGE model (Ref. [17] Helgeson JF, Juan F.; O’Fallon, Cheyney M.; Webb, David W.; Cutler, Harvey. (2017) Identifying and Quantifying the Resilience Dividend using Computable General Equilibrium Models: A Methdological Overview. 2nd International workshop on Modelling of Physical, Economic and Social Systems for Resilience Assessment. ).
} 


\section{Conceptual Approach}

The objective of the approach is to develop a method to evaluate WUI fire risk on a regional economy, focusing on how direct shocks ripple through the economy and cause indirect impacts. ${ }^{4}$ WUI-induced direct effects are largely observable; how the effects cascade into other sectors of the economy is not well-understood. The proposed approach provides a mechanism to systematically quantify the interplay between direct and indirect economic affects.

The approach is to simulate possible economic shocks that occur from large WUI fire events. The process is as follows:

Step 1. Identify a set of direct economic shocks caused by WUI fire

Step 2. Define a distribution (range) of shock intensity for each shock

Step 3. Simulate the direct shocks within a community using CGE methods

a. Vary shocks over all possible factorial combinations of intensity as defined in Step 2

Step 4. Measure net-losses to the economy for each factorial combination

a. Evaluate net-losses for overall economy and by sectors to measure indirect impacts

An example would be: (Step 1) evaluate direct impacts of ( $a$ ) housing loss and (b) outmigration; (Step 2) define distribution of the size of the housing loss and out-migration expected (e.g., uniform distribution spanning $-5 \%$ to $-10 \%$ ); (Step 3) iterate full factorial housing losses and out-migration through CGE model; (Step 4) measure change in key economic measures (e.g., employment, wages, GDP) for the overall economy and for individual sectors (e.g., tourism, retail sales, construction).

Additionally, two extra steps could be used to evaluate the relative importance of individual shocks and how they interact with others, along with an examination of the effect of different policy levers:

Step 5. Analyze net-losses as a function of shock intensity to determine the importance of individual shocks and cross-shock effects

Step 6. Evaluate (shock) risk mitigation economic stimulus to offset net-losses to determine cost-effective strategies

While the proposed approach could be modified to consider a previous or an expected event, the novelty comes from focusing on the generalized loss of functionality rather than a specific event. Previous events, particularly those extreme events, may not be strong

\footnotetext{
${ }^{4}$ The focus of the report is on WUI fires; however, the approach could be used to evaluate shocks from other natural and human-caused disruptions.
} 
predictors of future fire behavior. Accurate community-scale fire spread models present their own set of challenges (Ref. [26]). The focus on functionality and recovery is consistent with best practices in the planning for community resilience (Ref. [27, 28]).

\section{Computable General Equilibrium Model}

The CGE model represents a series of supply and demand relationships, which clear the market (supply equals demand) through adjustments to prices and quantities (Ref. [17]). Figure 1 provides a general conceptualization of a CGE model. The 'SAM Region' defines economy of interest (ie., the study area). Flows to and from areas outside the SAM region ('Rest of World') are allowed. Households and producers are linked thorough product and capital markets through savings (investments) and sales. Government is linked to households and producers through taxes and transfers. The social accounting matrix (SAM) represents the flow of transactions (see Section 4.1), while a set of elasticities dictates the size of the flows from behavioral responses (see Section 4.2).

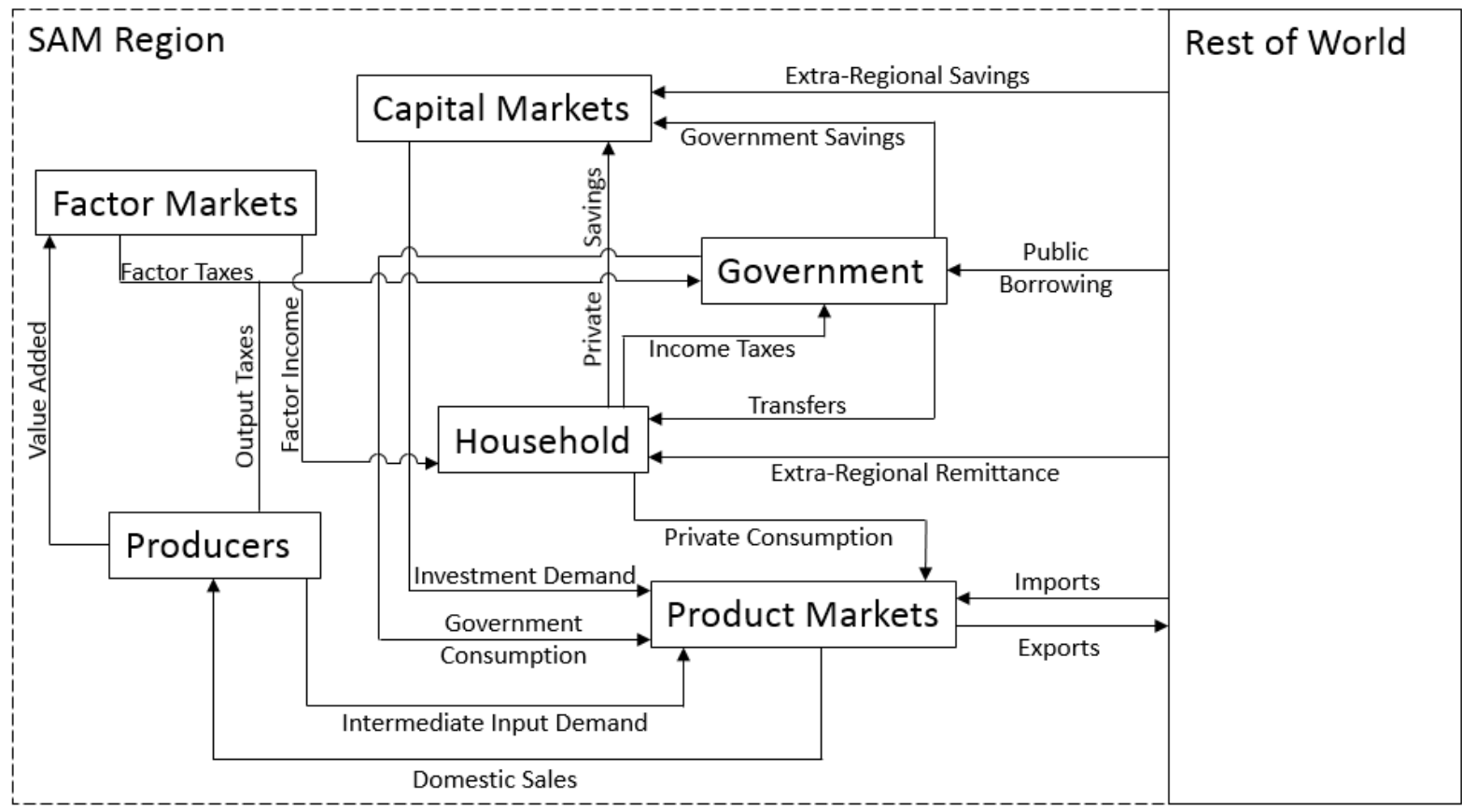

Figure 1: Schematic of a CGE Model

\subsection{Social Accounting Matrix}

Figure 2 presents a reduced form representation of the social accounting matrix (SAM) used in a CGE model. Within the SAM, payments are represented as made from columns to rows. For instance, the "Sales and Property Taxes" segment represent payments from the columns "Goods", "Trade", and "Other" to the rows "Fed", "State”, and "Local." 5 Not all flows occur within the SAM region. For instance, it may be necessary to allow for capital outflows from

\footnotetext{
${ }^{5}$ The rows and columns represented in the example SAM are not necessarily going to be found in every SAM. Some may be further aggregated, disaggregated, or otherwise omitted based on the purpose of the analysis.
} 
the SAM by incorporating household expenditures or public expenditures to the 'Rest of World' (ROW). The components of the SAM, as depicted in Figure 2 and as they relate to WUI fires, are detailed below. The SAM is considered 'balanced' when receipts and payments are equal.

\subsubsection{Input-Output}

The Input-Output (IO) element of the SAM provides the fraction of input (in dollars) each industry uses from other industries to provide one dollar of output. This relationship is vital to the SAM as the links between industries serve to propagate shocks throughout the entirety of the region's economy. Input-output data can be brought in at the NAICS (North American Industry Classification System) code level as reported by the Bureau of Economic Analysis (BEA), or it can be aggregated by NAICS code into larger collections of industries, for instance, wholesale businesses, food manufacturing, or information services. The latter approach is favored, as the dimensions of the SAM areare a function of the number of NAICS codes included, and a larger SAM is more difficult to balance. Furthermore, some NAICS codes may not be large enough to warrant their individual inclusion. Input-output data are available from the BEA.

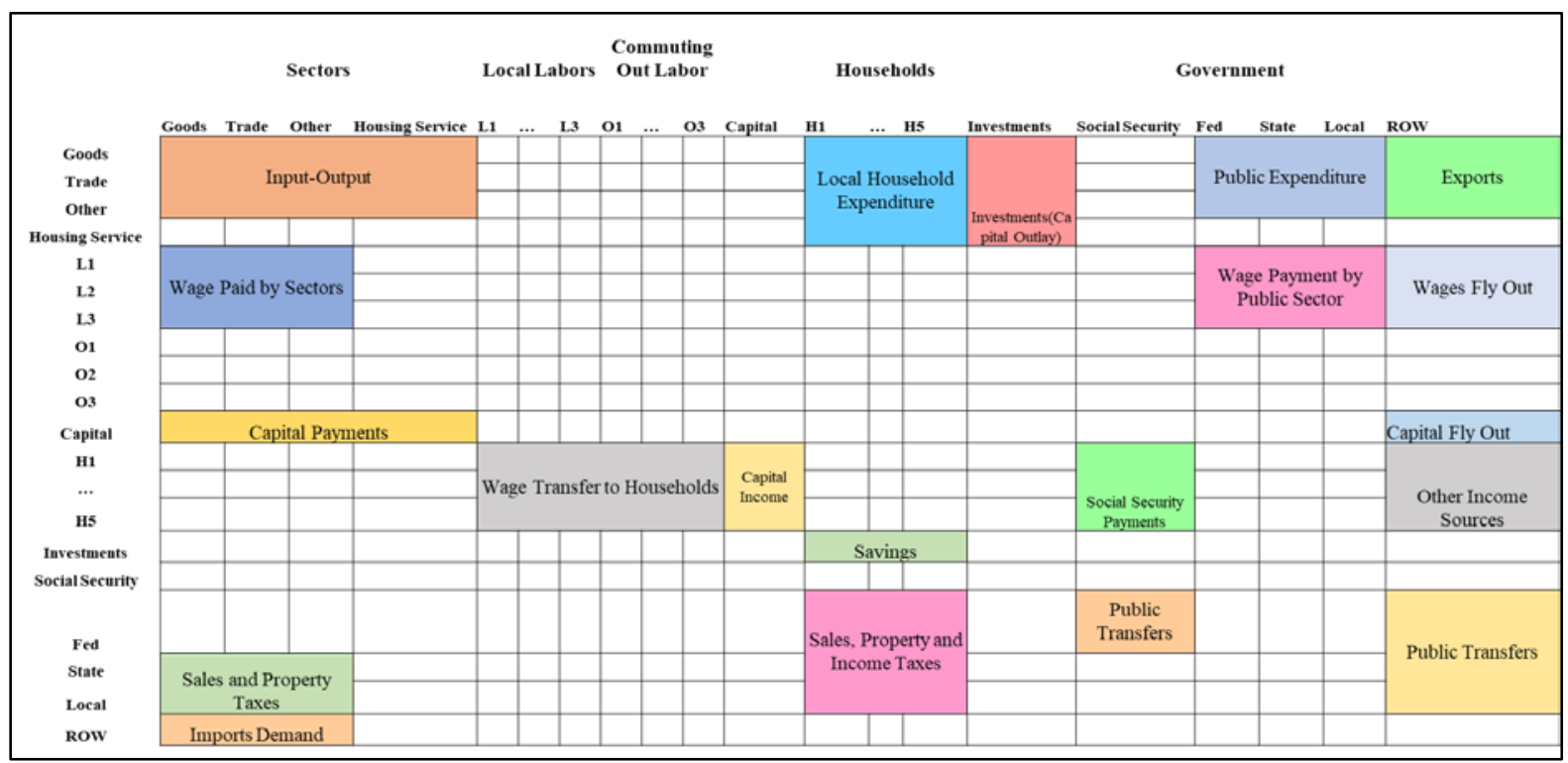

Figure 2: Conceptualization of the Social Accounting Matrix (SAM)

\subsubsection{Household Expenditures}

Household expenditures are payments made by a household to an industry as defined by the aggregated IO segments. These represent the purchases of goods and services within the economy by households within the study area. Thus, they are inter-regional purchases and do not include any purchases made by households outside the economy. This distinction is important. From a modeling perspective, it is important to capture how much of the economy is driven locally and how much is driven by outside entities. WUI fires can disrupt the flow of goods and services to households through business closures or evacuations. 


\subsubsection{Investments}

Investments represent payments made to industries for capital outlay-i.e., funds spent for acquiring, maintaining, repairing, or upgrading capital assets. Not included in the example SAM are investment payments by industries, as well as payments by industries to the ROW. It is unknown whether WUI fires disrupt investments in an area.

\subsubsection{Public Expenditures}

Public expenditures represent the portion of the economy driven by governmental purchases of industry outputs for government projects, liabilities, or programs. Pensions, materials for public works projects, or any government payment made to an industry within the region are accounted for in this section of the SAM. Public expenditures would include funding for presuppression and suppression efforts.

\subsubsection{Exports}

Exports are any purchases of industrial outputs from the region being studied by any household, government, industry, or other economic actor outside of the studied region. No distinction is made based on where the ROW purchaser is located. The model inherently divides the economy into the regional economy of interest and the rest of the world. It is possible to divide the ROW column into subsections if desired, for instance exports within the state, country, or even other regions of the world, but in examining the local economy such distinctions are usually not necessary. WUI fire could cause business interruption and closures, which could affect exports.

\subsubsection{Wages Paid}

Wages paid ${ }^{6}$ represents the total payments from industries or government to the various labor groups represented in the SAM. 'Wages Fly Out' refers to wage payments to employees who live outside of the study region, but otherwise receive their wages from an industry within the study region. The 'Commuting Out Labor' columns capture commuter wages; however, they are not necessary if commuter wages are not of concern in the study. In such a case commuter wages can be folded into the "Wages Fly Out" segment. Business closures or evacuation could affect wages.

\subsubsection{Capital Payments}

Capital payments section refers to any payments made by industries as part of a capital expenditure. These include payments for land, buildings, equipment, or any other fixed asset used by the industry. Property tax payments are not included in this portion of the SAM, as tax payments are made directly to the government, while capital payments are typically not public transactions. 'Capital Fly Out' serves the same function as 'Wages Fly Out' by capturing all capital payments made to actors outside the region being studied. Structure loss due to fire damage could affect capital payments.

\subsubsection{Sales and Property Taxes}

Sales and Property Taxes (lower left green box in Figure 2) include payments by each industry sector and housing services to state and local government. These values will change as sectors grow or tax rates are adjusted. Tax revenue collected is then used to meet public expenditure requirements, public sector wages, social security payments, and public transfers to local households and the rest of the world. Sales and property taxes are likely to be

\footnotetext{
6 "Wages Paid by Sectors" and "Wages Payments by Public Sector” This footnote sounds incomplete
} 
impacted directly by shocks to the built environment (structure loss), out-migration, and business interruption. To the extent that structure loss leads to lower aggregate property values in the wake of a wildland fire event, we may expect property taxes paid by various economic sectors to local and state government to fall. Taxes are not collected on the sales interrupted by wildfire. The local and regional budgets for public services may thus be diminished after a wildland fire.

\subsubsection{Import Demand}

Import demand is the demand of goods and services from ROW. How local sectoral demand for imports evolves after wildland fire-induced structure loss is ambiguous. Shuttered businesses demand fewer inputs, whether imported or local in origin. However, rebuilding efforts often require the import of materials and labor from beyond the impacted region. This ambiguity can be resolved through the CGE model. The effects of structure loss will depend on the sectors in which structures are lost and the differential response of all sectors to losses in any given part of the local economy. For example, structure loss in the retail sector will entail different impacts on the trajectory of recovery than will similar losses in the local construction sector.

\subsubsection{Wage Transfers}

Households earn income from wage transfers from their constituent laborers and capital income. The net effect of wildfire related shocks on wage transfers and capital income will depend on which sectors of the economy are impacted and how recovery is enacted. Disrupted businesses will likely reduce payments to laborers, but some sectors may scale-up production to aid in the recovery process.

\subsubsection{Capital Income}

Capital income is the income generated from investments into capital assets. Capital income too will respond ambiguously to wildfire events. Rental incomes on destroyed properties will clearly fall, but owners of the remaining housing stock may realize disaster-related scarcity rents after the housing supply contracts. This result will generally apply to other types of capital rents as well.

\subsubsection{Savings}

Household savings are assumed to equal investments. If savings are drawn upon to facilitate suppression, evacuation, or recovery efforts, we can expect investments in other activities to decline. The share of investments made in the local economy versus the stock market or other capital markets in the rest of the world will determine the extent of wildfire impacts on the local economy through the savings and investment channel.

\subsubsection{Sales, Property and Income Taxes}

Households pay sales, property, and income taxes to the federal, state, and local government. When structures are lost, business is interrupted, or out-migration occurs, the value and composition of these tax payments will change, impacting the revenues available for expenditure by public organizations.

\subsubsection{Social Security Payments \& Public Transfers}

Generally, social security payments into the community under study will remain constant after a wildfire event in the absence of out migration or loss of life by beneficiaries. Other 
income sources and public transfers from the rest of the world to the study area should remain constant if the wildfire event is contained within the region.

\subsection{Elasticities}

Elasticities are central parameters in any model of regional economies. An elasticity is a measure of how a given variable of economic interest responds to changes in other economic variables. Elasticities capture the sensitivity of economic phenomena to each other.

The CGE model contains parameter values for many key elasticities. The first such parameter in our CGE model is the income elasticity of demand, which captures the sensitivity of demand for a given product or service to changes in the income of households. The formula for this elasticity is the percentage change in quantity demanded divided by the percentage change in household income. Higher positive values indicate that demand is relatively more responsive to changes in income.

For normal goods and services, increases in household income will correspond to higher demand for the good. Necessary goods exhibit a positive income elasticity of demand, generally bounded by zero and one. Luxury and superior goods tend to have income elasticities of demand greater than one, indicating that a given percent change in income corresponds to a larger percent change in quantity demanded. Food and shelter are clearly necessities. Sports cars and dinners at gourmet restaurants are better classified as luxury or superior goods. By comparison, inferior goods have an income elasticity of demand less than zero. As household incomes rise, the quantity demanded of goods and services perceived as inferior tends to fall. Intuitively, as households move up in the income distribution, the quantity demanded of public transportation, low cost foods, and financial sector services with unfavorable terms are expected to fall.

How households and firms respond to changes in specific price levels is crucial to modelling regional economies confronted with hazards like wildfires. Changes in the domestic price level associated with the impacts of disaster will influence both the demand for imported substitutes and export demand for local production. Import and export elasticities will determine how a local shock is propagated beyond the region impacted by wildfires directly. The price of land and labor may change significantly as wildfire suppression calls for the input of local resources and structure loss is met with efforts to rebuild. The responsiveness of labor supply to the wage rate and tax level is also salient to our model of community response to wildfire.

Other important parameters to note include the elasticity of in-migration to the unemployment rate and after-tax earnings. Cross-price elasticities, indicating the responsiveness of quantity demanded of one good or service to changes in the price of a substitute or complement are also incorporated into CGE models. A non-exhaustive list of common elasticities modelled in a CGE setting follows.

\section{Common Elasticities in CGE Models}

- Income elasticity of demand

- Export elasticities with respect to domestic price 
- Import elasticity with respect to domestic price

- $\quad$ Price elasticity of demand for land

- $\quad$ Price elasticity of demand for labor

- Labor supply elasticity with respect to average wage

- Elasticity of in-migration to after tax earnings

- Elasticity of in-migration to unemployment

- Elasticity of labor supply with respect to taxes

- Cross-price elasticity of demand

Obtaining accurate estimates of elasticity values is a common empirical endeavor in economics. The data requirements and methods needed to produce elasticity values can limit the frequency of their estimation, leading researchers to employ older values for modeling purposes. Furthermore, personal or household heterogeneity in any given elasticity measure may render a given estimate unrepresentative of some segments of the communities under study. It is not unrealistic to expect the price elasticity of demand for a given good or service to vary with the tastes and preferences of the population under study.

In recognition of these limitations, sensitivity analysis is often conducted on elasticity values. One approach, used in the California Dynamic Revenue Analysis Model (DRAM; Ref. [29]), is to run the analysis with alternate values of key elasticities. If the model results change significantly when these elasticities are increased or decreased by $50 \%$, the mechanisms modeled are considered sensitive to the assumptions made. While it is possible that experiencing wildfires changes the elasticities of impacted firms and households, the CGE model currently under development is not designed to accommodate dynamics in these measures of responsiveness. Effectively, we assume that impacted communities will target recovery efforts in a manner that seeks to return the local economy to its pre-event trajectory.

\subsection{Other Inputs}

This section covers supplemental data directly required to run the CGE model that are not found directly in the SAM or part of the elasticities. These include data describing the capital commodities matrix (CAPCOM), employment, the job core, and household data. Sales tax data are derived from local Comprehensive Annual Financial Reports (CAFR).

\subsubsection{CAPCOM}

The CAPCOM, or capital commodities matrix, is similar to the IO data in that it defines the interdependencies between industries. The difference is that the CAPCOM quantifies the number of commodities and industry purchases for investment from other industries. In that way it links the interdependencies on new investments over the basic input required for production. Data for the CAPCOM are based on the BEA’s “Capital Flow” data.

\subsubsection{Labor (Employment, Working Households, and Job Core)}

Labor inputs, outside of those in the SAM itself, include the total labor supply and the labor pool (job core). The labor pool provides the total employment by industry and wage group 
for the regional economy in question. Data for the labor supply can come from multiple sources, including Public Use Microdata Sample (PUMS) data, Quarterly Census of Employment and Wages (QCEW) data, Bureau of Economic Analysis (BEA), and Bureau of Labor Statistics (BLS) data. Data on the number of working and non-working households in each household group are also required. The household data account for unemployment, retirees, and other circumstances where a household does not actively participate in the work force. The "Job Core" matrix relates the number of working households to the number of workers in the economy.

\subsection{Data Sources}

A comprehensive look at the data sources required to build a SAM can be found in Helgeson et al. [17].

Table 1 provides a linkage structure for what data sources are used to construct each sector of the SAM. Entire pre-built SAMs can be obtained from third party sources as well.

Table 1: SAM Segment Data Linkages

\begin{tabular}{|c|c|}
\hline SAM Sector & Data Source(s) \\
\hline Input-Output & BEA Input-Output Table \\
\hline Local Household Expenditures & Consumer Expenditure Survey \\
\hline Investments (Capital Outlay) & CAPCOM from BEA Commodities Table \\
\hline Public Expenditures & BEA Input-Output Table \\
\hline Exports & Adjusted to balance SAM under assumption of equilibrium \\
\hline Wages Paid by Sector & BLS, PUMS, or QCEW data \\
\hline Wage Payment by Public Sector & BLS, PUMS, or QCEW data \\
\hline Wages Fly Out & Adjusted to balance SAM under assumption of equilibrium \\
\hline Capital Payments & CAPCOM from BEA Commodities Table \\
\hline Capital Fly Out & Adjusted to balance SAM under assumption of equilibrium \\
\hline Wage Transfer to Households & BLS, PUMS, or QCEW data \\
\hline Capital Income & CAPCOM from BEA Commodities Table \\
\hline Social Security Payments & Based on social security tax rate \\
\hline Other Income Sources & Adjusted to balance SAM under assumption of equilibrium \\
\hline Savings & Difference between wages and expenditures \\
\hline Sales and Property Taxes & CAFR, Assessor's Office \\
\hline Sales, Property and Income Taxes & CAFR \\
\hline Public Transfers & CAFR \\
\hline Public Transfers (Fly Out) & CAFR \\
\hline Import Demand & Adjusted to balance SAM under assumption of equilibrium \\
\hline
\end{tabular}




\subsection{Spatial Considerations}

Traditional CGE models are non-spatial, meaning the locations of homes and business, for example, are not considered. When considering the impacts from natural hazards, spatial considerations are important, as the economy may not be impacted from the hazard equally.

It is possible to add spatial components to a CGE model by decomposing the economic region of interest into smaller regions and adding interactions among them. Creating subregions allows specific shocks to target specific areas within the economy and propagate through the whole economy. An example would be a shock that removes a portion of the workforce located in a lower wage region and observing how that impacts not just the regional economy, but also any other sub-regions that may have demanded that labor.

While such an analysis is interesting, including it in the proposed analysis creates an issue. Developing the final output for the proposed study requires several runs of the CGE model, and the added complexity of the spatial components may make the SAM computations unwieldy, especially if a full-factorial analysis is done. The sub-regional impacts are also not in the scope of the current analysis. To alleviate this issue a "pseudo-spatial" CGE analysis is considered. Instead of adding spatial components to the SAM, the region in question is analyzed using geographic information system (GIS) software. It is divided into sub-regions based on zoning and census data to create rough areas of commercial, industrial, retail, highincome residential, and other pertinent sub-regions. Assessor data allows land values and larger companies to be placed within specific regions if desired, but a naïve assumption may be made that industries are evenly distributed through the region.

Once the regions are created, shocks for the non-spatial SAM can be defined by using the GIS software. Using the GIS software to determine the area assumed damaged by the fire with the appropriate overlays allows the shock to be "simulated" by knowing what parcels have been burned. $f$ the naïve assumption is used, then the shock will simply be a fractional loss of labor, housing, etc. equivalent to the fractional loss of area in the GIS sub-region, provided the right inputs are altered. This abrogates the need to add a highly detailed fully spatial SAM, and instead allows a batch of shocks to be applied to the naïve SAM that roughly approximate similar losses. While the final output will not allow each sub-region to report its impacts, the overall effect on the economy should still be available. More complex analyses, such as looking at lost linkages between sub-regions through road or power networks will also be infeasible, but they are beyond the scope of the current project.

By using a simplified SAM and reducing the sub-regional impacts to a regional shock based on a spatial GIS analysis, the calculations of the CGE are simplified and a larger batch of shocks can be run in succession with less of a penalty on computation time. This allows for a results to be analyzed to be built faster. The analysis at this point is at a proof of concept state, and if the method proves viable, then utilizing more complicated spatial CGE models will be just as beneficial, and likely more so.

\section{Simulating WUI Shocks and Mitigation in a CGE Model}

The heart of CGE modeling is to observe how the economy reacts to designed shocks (i.e., how it adjusts back to equilibrium). WUI fires can cause several different shocks, as can risk mitigation efforts. A set of potential shocks and mitigation activities are described below. 


\subsubsection{WUI Shocks}

We consider three possible shocks from WUI fire: structure loss, business interruption, and out-migration. While residents can be effectively evacuated from the path of wildland fires, the built environment must contend with hazards in situ. Despite the best efforts of homeowners, community planners, and fire service personnel, severe wildland fires can impact communities drastically through the loss of structures. The economic and psychological impacts associated with losing one's home or business to wildfire can be severe and widely felt in local communities. The indirect effects of wildland fire on communities that have lost large portions of their structural base may be felt for years, as the rebuilding process may exceed local pre-event construction capacity.

\subsubsection{Structure Loss}

Structure loss is a root shock that can cause other shocks to the local economy. Families that have lost their primary residence or vacation home may decide not to return to the community, leading to out-migration.

The full extent and complexity of the indirect effects of structure loss are difficult to anticipate, and the use of modelling tools such as regional CGE models can facilitate the systematic investigation of wildland fire impacts on communities in the WUI.

The most straightforward way to model structure loss may be as a reduction in the initial capital stock. Holding factor demand constant, changes in the capital stock will lead to changes in the equilibrium quantity and price (rental rate) of capital. Changes in the value and quantity of capital will impact the production and consumption decisions of all firms and households in the CGE model.

\subsubsection{Business Interruption}

Businesses may lose facilities that are critical to their production capacity, interrupting output and causing revenue losses entailing impacts on firm owners, managers, employees, customers, and other community stakeholder groups. Out-migration and business interruption may compound each other as members of the labor force relocate to find new jobs and homes. Furthermore, it is important to note that even in the absence of structure loss, families may decide to move away from a community they fear will continue to face the risk of wildland fires and businesses may find that their business models require fire-related adjustments even if all their structures remain sound. Tourism-related business, for instance, may find demand evaporating as wildland fire and smoke reduces the amenity value of local forest and recreational resources.

\subsubsection{Out-Migration}

The household is a fundamental unit of analysis in the context of the CGE model. Outmigration is clearly one mechanism through which the number of households in a regional economy may change. One strategy for modeling out-migration would be to incorporate an out-migration elasticity with respect to structure loss. Needed would be an understanding of what the impact of losing a home means for the propensity for a family to leave the community. Another method might be to adjust the total household count as a function of how many structures are lost. For a given size shock to the stock of structures in the community, the number of households that decide to stay and leave can be modeled directly and subjected to sensitivity analysis. 


\subsubsection{Risk Mitigation}

The shocks presented in the previous section are all effects of a wildland fire occurring near a populated area. While some effects may be negligible based on the nature of the event, it is reasonable to expect that all of them may manifest in some way, even if it does not reach the level of a regional impact. For that reason, the mitigation of these shocks is an important consideration for any WUI community.

Since all the mitigation measures are meant to reduce the impacts of fire, a base scenario (equilibrium without a shock) is required to properly account for any benefit. These base events can be easily pulled from the three shocks presented in the previous section.

Essentially each shock will be a base scenario for what the mitigation measures would do for that specific shock. All measures also require altering spending within the economy. Such a change will invariably alter the economy even if no fire occurs. A separate run of the altered economy without any shocks is needed to understand the impacts of the spending change on the base state economy. This is required since altering the SAM to account for changes in spending invariably alters the base economy requiring both a comparison of the unaltered base state to the new base state to, and the unaltered base state to the post-shocked economy.

\subsubsection{Insurance}

Residents or businesses in the WUI may purchase insurance to offset the losses from damage of a wildland fire. For residents this will typically take the form of homeowner's or renter's insurance, while businesses may insure their physical structures, inventory, or even their ability to do business in the case of business interruption insurance. Such actions can have a collective impact on the regional economy through a few linkages.

Homeowner's or renter's insurance allows the insured to offset that loss of structure damage. This may allow them to remain in the region, or even rebuild in the same location, with greater ease, though there is no guarantee that they will do so. They will most likely face higher premiums in the future if they rebuild, but insurance does at least present the option. Businesses may also be able to remain solvent and active in the regional economy if insured. As with homeowner's insurance, an insured business may not return. Depending on the nature of the fire and its impact on the region, there is a possibility of a business reopening and then failing due to the adverse business conditions that can persist after the event.

While the benefits of insurance are understood, it is not straightforward to measure their impact within the CGE model. The reason is the CGE model being considered is not dynamic in nature, and thus temporal relationships are difficult, if not impossible to draw out. Given that some form of damage must occur prior to an insurance payout, its benefits occur in the recovery stage as opposed to the event stage.

One means of simulating the effects of insurance is to first increase spending on the appropriate segment in the SAM relative to a base scenario as defined by the pure shock analysis. A financial services sector or insurance sector may be appropriate, or insurance payments could be wrapped up in the housing services payments in the SAM. Anytime the SAM is adjusted it needs to be rebalanced, and assuming income remains fixed, any additional spending on insurance will have to be balanced by reduced spending on other industries. Amenities and entertainment are the most likely targets. 
With the insurance spending altered, some change must be made to account for other cobenefits within the CGE calculation. A co-benefit of insurance is the increased retention of residents and businesses in the recovery stage, but it is impossible to directly apply the retention effect. Instead it will need to be proxied in the CGE calculations. This could be achieved by artificially suppressing the loss of housing stock or businesses due to the fire relative to the chosen base scenario. Since the final output of the CGE is the "shocked" economies equilibrium, we will assume that the "saved" structures represent those that were able to be rebuilt and participate in the post-fire economy. There are limitations to this assumption, namely reconstruction can take several years following a major fire.

Most insurers operate over national or global scales to diversify their portfolio and reduce risks to their business models. Effectively, insurance payments may be modelled as an influx of cash into the regional economy from the rest of the world. Within the SAM, these cash transfers to the local economy may be recorded as "Other Income Sources" from the rest of the world to households. Households then allocate these insurance claim payments between local expenditures, savings, and taxes. The composition of local household expenditures made with the insurance claim payments will vary as households individually decide whether to rebuild and which lost items to prioritize in the recovery phase. Local expenditures from households to the construction sector are expected to use a significant share of these insurance claim payments should rebuilding be preferred to out-migration. Savings could decline as households draw on accumulated funds to cover the immediate costs of wildfire before insurance claims are paid. Property taxes paid on destroyed properties may fall. Sales and income tax receipts may also fall as households and employers are displaced or businesses are interrupted.

One challenge to modelling the impacts of these insurance payments is that assumptions must be made with respect to the timeline of critical events. The wildfire shocks the local economy in period zero. However, there is no certainty in the timing of when insurance claims are filed and eventually paid to households. There is uncertainty surrounding whether households and firms will choose to rebuild or leave the region, and how long it will take the local construction industry to replace structures lost to the fire. The fact that model periods are not of a clearly defined time step further complicates modelling and analytical efforts.

These sources of uncertainty can be addressed by recovering plausible distributions of the underlying phenomena through consultation of existing literature and data resources concerning the recovery process. The propensity of households to rebuild rather than engage in out-migration can be observed in case studies of past wildfire events. Distributions for the duration between wildfire events and claims being paid to households is also recoverable from administrative and public data sources. Reconstruction times for typical housing facilities may be obtained from industry averages or experience. If construction capacity is destroyed by the wildfire event or capacity from the ROW is attracted to the recovery effort, local construction time distributions may differ substantially from the national or regional averages established in the pre-event periods. While actual build times will be tied to the resources and capabilities of the construction sector, the difficulty of dynamically adjusting the expected restoration time in line with sectoral capacity may require the employment of simpler assumptions. 
A naïve approach to modelling structure restoration times might be to assume that half of destroyed structures are rebuilt by the median construction time following the wildfire event. However, as the time step in the CGE model under development is not defined in a clear manner (one-week, one-month, etc.), a median restoration time of one-year would need to be benchmarked against the median time that a regional economy shocked by wildfire takes to reach its post-event equilibrium. Any estimate of typical restoration times may be highly dependent on local conditions. If a typical regional economy of a given scale takes two years to reach a new steady state, and the new equilibrium is reached after 48 time periods, we would want to model $50 \%$ of the homes being rebuilt by the $24^{\text {th }}$ period. However, the rate of structure restoration will impact the time between equilibriums. Resolution of this feedback mechanism will present a challenging but ultimately assailable hurdle for future research.

\subsubsection{Defensible Space ('Firewise')}

The other forms of mitigation are much simpler to understand and implement. Both Firewise and government mitigation efforts are implemented to prevent the loss of structures to begin with. Firewise is a voluntary set of standards and practices that make a residential property on the WUI "defensible," which is to say that it can be defended from an approaching fire by a fire department or the owners of the land. This definition makes the CGE modeling straightforward. After choosing the base scenario to start from, the SAM is rebalanced after increasing household spending on the industries and government entities (local fire department, city planners for permitting, etc.) that would be required to implement the Firewise standards while reducing spending in amenities.

Because Firewise is meant to be implemented at the boundary of the WUI, a spatial analysis in GIS will identify a subset of those structures that might be expected to implement and then iterate through a percentage of homes assumed to have implemented the standards. This rate of implementation can then be assigned to a set reduction in housing loss that can be passed into the CGE calculation.

\subsubsection{Government Intervention}

Government mitigation works much the same way as the Firewise mitigation with a few key differences. The first is where spending changes occur in the SAM. Government spending will have to be increased through the appropriate columns and rows in the SAM, which means there will have to be an increase in taxes to pay for the increased spending. In theory spending cuts in other areas could offset the cost of the new mitigation measures, but the assumption here will be that previous spending is held constant. Outside funding from federal, state, or county government grants may also be increased to balance out the new spending. The other key difference is that government mitigation is not necessarily limited to residential properties. As such, reductions in business losses over the base scenario are also passed into the CGE model.

\section{Model Outcomes}

The outcome of a CGE model is the equilibrium of the regional economy. The shocks and mitigation measures implemented in this analysis contribute to a "new" equilibrium over that of the non-event state of the economy. From this, various outcomes can be examined. Changes in the size of the labor force, changes in average wages, changes in the profile of 
industries within the region can all be examined among with many other facets of the economy. In the case of mitigation, these variables must be compared with the economic impact of a fire in a non-mitigation scenario to look for improved resilience of the economy. Without running the analysis, it is difficult to say what outputs are the most interesting or what results stand out, however there are certain indicators of economic health that will be the initial focus: labor demand, wages, tax revenue, and household spending.

Furthermore, the number of model periods between the incidence of the wildfire shock and the attainment of long-run equilibrium will offer insight into the relative longevity of different types of wildfire damages. While the exact time to reach the new equilibrium cannot be obtained from the non-dynamic CGE model, the relative lengths of time to recovery provide additional information to aid a community in targeting resilience enhancing measures. The model outcomes of interest may include surfaces for both the completeness and speed of recovery. We are interested in observing the extent to which the post-event equilibrium wage rate and other key outcomes deviate from that of the pre-event equilibrium. The event attributes that accelerate or slow recovery warrant some investigation, even if the precise number of months to full restoration cannot be estimated explicitly.

\section{Loss Surfaces \& Decision-Making}

Performing a full factorial set of simulations (across the direct economic shocks) has the potential to generate a lot of data. In the case of one direct shock and one output measure (e.g., average wages) a simple vector of data is produced. For two shocks and one output, a matrix is produced. Anything larger and a multi-dimensional surface space is required. The shape of the simulation results is not important. What is important is each element within the surface represents an output value for a unique combination of shocks and their intensities (e.g., $7 \%$ housing stock loss, $5 \%$ business closure in retail sales, $15 \%$ population outmigration). These surfaces can be analyzed to understand potential economic vulnerabilities-i.e., thresholds that result in catastrophic loss. Simulating risk mitigation scenarios along with various direct shocks can be used to determine the optimal intervention intensities. Combined with intervention cost data, cost-effective risk mitigation, strategies could be identified.

\section{Limitations}

Left for future research is a proof-of-concept case-study. However, even in the absence of a rigorous analysis of such work, the approach offers a few limitations. First, the approach is data intensive. This is true of CGE modeling in general. Analyzing a greater number of industrial sectors increases complexity, as does modifying the CGE model to be spatially explicit. Second, the results generated are specific to the location selected. However, this limitation often exists for empirically-based methods. Third, model validation would require a comparison to an analytical solution or to an observed shock (e.g., compare changes in labor pre- and post-event for an actual WUI fire). Fourth, not all elements of the CGE have a means to address uncertainty (e.g., the SAM); however, sensitivity analysis could be performed to evaluate and identify key assumptions. 


\section{Conclusions}

This report developed an approach to evaluate the direct and indirect impacts from wildlandurban interface (WUI) fire, resulting from the loss of functionality of the built environment, for a regional economy. Given the lack of understanding of the magnitude of indirect losses from WUI fires, and how they are related to the observable direct effects, this approach fills the void with a method to systematically quantify their relationship. The use of a computable general equilibrium (CGE) model allows for simulation of various possible economic shocks resulting from the temporary or permanent loss of the built environment. It also allows for behavioral changes of the local population due to fire risk. The output from such an approach will facilitate a better understanding of potential vulnerabilities within a community. For example, the approach could identify thresholds of functionality that if exceeded would result in catastrophic loss. In addition, simulation of risk mitigation scenarios (allowing for a resilience in functionality) could be used to determine optimal intervention strategies. Combined with intervention cost data and cost-effective risk mitigation, strategies could be identified. Future research will develop a proof-of-concept to explore the approach, with a focus on using the model output to inform decision-making for improving community resilience against WUI fires. 


\section{Acknowledgments}

The authors wish to thank all those who contributed so many excellent ideas and suggestions for this report. Special appreciation is extended to Juan Fung of NIST's Applied Economics Office and Kathryn Butler of the NIST's Fire Research Division. The authors also wish to thank Nicos Martys, of the NIST’s Materials and Structural Systems Division, for his review. 


\section{References}

[1] Thomas D, Butry D, Gilbert S, Webb D, Fung J (2017). https://doi.org/10.6028/nist.Sp.1215

[2] Butry DTM, D.E.; Prestemon, J.P.; Pye, J.M.; Holmes, T.P. (2001) What is the Price of Catastrophic Wildfire? Journal of Forestry (November):9-17.

[3] Kent BG, Krista; McCaffrey, Sarah; Martin, Wade; Calkin, David; Schuster, Ervin; Martin, Ingrid; Bender, Holly Wise; Alward, Greg; Kumagai, Yoshitaka; Cohn, Patricia J.; Carroll, Matt; Williams, Dan; Ekarius, Carol. (2004) Social and economic issues of the Hayman Fire. In: Graham, Russell T., ed. Hayman Fire Case Study. Gen. Tech. Rep. RMRS-114. US Department of Agriculture, Forest Service, Rocky Mountain Research Station: 315-396.

[4] Davis EJ, Moseley C, Nielsen-Pincus M, Jakes PJ (2014) The Community Economic Impacts of Large Wildfires: A Case Study from Trinity County, California. Society \& Natural Resources 27(9):983-993. https://doi.org/10.1080/08941920.2014.905812

[5] Keegan CEM, T.A.; Hearst, A.L.; Fiedler C.E. (2004) Impacts of the 2000 Wildfires on Montana's Forest Industry Employment. Forest Products Journal 54(7/8):26-28.

[6] Pugliese A, McCann L, Artz G (2015) Impacts of national forests in the West on county population and employment. Forest Policy and Economics 50:62-69. https://doi.org/10.1016/j.forpol.2014.08.002

[7] Nielsen-Pincus M, Moseley C, Gebert K (2013) The Effects of Large Wildfires on Employment and Wage Growth and Volatility in the Western United States. Journal of Forestry 111(6):404-411. https://doi.org/10.5849/jof.13-012

[8] Nielsen-Pincus M, Moseley C, Gebert K (2014) Job growth and loss across sectors and time in the western US: The impact of large wildfires. Forest Policy and Economics 38:199-206. https://doi.org/10.1016/j.forpol.2013.08.010

[9] Duffield JW, Neher CJ, Patterson DA, Deskins AM (2013) Effects of wildfire on national park visitation and the regional economy: a natural experiment in the Northern Rockies. International Journal of Wildland Fire 22(8). https://doi.org/10.1071/wf12170

[10] Loomis J (2004) Do nearby forest fires cause a reduction in residential property values? Journal of Forest Economics 10(3):149-157. https://doi.org/10.1016/j.jfe.2004.08.001

[11] Kim Y-SW, Aaron (2005) Them Impact of Forest Density on Property Values. Journal of Forestry (April/May):146-151.

[12] Donovan GHC, P.A.; Butry, D.T. (2007) Wildfire Risk and Housing Prices: A Case Study from Colorado Springs. Land Economics 82(2):217-233.

[13] Hjerpe E, Kim Y-S, Dunn L (2016) Forest density preferences of homebuyers in the wildland-urban interface. Forest Policy and Economics 70:56-66. https://doi.org/10.1016/j.forpol.2016.05.012

[14] Stetler KM, Venn TJ, Calkin DE (2010) The effects of wildfire and environmental amenities on property values in northwest Montana, USA. Ecological Economics 69(11):2233-2243. https://doi.org/10.1016/j.ecolecon.2010.06.009

[15] Kalhor EH, B.P.; Valentin, V.; Berrens, R.P. (2018) Investigating the Effects of both Historical Wildfire Damage and Future Wildfire Risk on Housing Values. International Journal of Ecological Economics and Statistics 39(1):1-25. 
[16] Koks EE, Carrera L, Jonkeren O, Aerts JCJH, Husby TG, Thissen M, Standardi G, Mysiak J (2016) Regional disaster impact analysis: comparing input-output and computable

general equilibrium models. Natural Hazards and Earth System Sciences 16(8):1911-1924. https://doi.org/10.5194/nhess-16-1911-2016

[17] Helgeson JF, Juan F.; O’Fallon, Cheyney M.; Webb, David W.; Cutler, Harvey. (2017) Identifying and Quantifying the Resilience Dividend using Computable General Equilibrium Models: A Methdological Overview. 2nd International workshop on Modelling of Physical, Economic and Social Systems for Resilience Assessment.

[18] Rose AL, Shu-Yi (2005) Modeling Regional Economic Resilience to Disasters: A Computable General Equilibrium Analysis of Water Service Disruptions. Journal of Regional Science 45(1):75-112.

[19] Carrera L, Standardi G, Bosello F, Mysiak J (2015) Assessing direct and indirect economic impacts of a flood event through the integration of spatial and computable general equilibrium modelling. Environmental Modelling \& Software 63:109-122. https://doi.org/10.1016/j.envsoft.2014.09.016

[20] Hallegatte S (2008) An adaptive regional input-output model and its application to the assessment of the economic cost of Katrina. Risk Anal 28(3):779-799. https://doi.org/10.1111/j.1539-6924.2008.01046.x

[21] Hallegatte S (2014) Modeling the Role of Inventories and Heterogeneity in the Assessment of the Economic Costs of Natural Disasters. Risk Analysis 34(1):152-167.

[22] Akhtar R , Santos JR (2012) Risk-based input-output analysis of hurricane impacts on interdependent regional workforce systems. Natural Hazards 65(1):391-405. https://doi.org/10.1007/s11069-012-0369-0

[23] Belasen ARP, S.W (2009) How Disasters Affect Local Labor Markets: The Effects of Hurricanesin Florida. The Journal of Human Resources 44(1):251-276.

[24] Ewing B, Kruse J, Thompson M (2003) A comparison of employment growth and stability before and after the Fort Worth tornado. Global Environmental Change Part B: Environmental Hazards 5(3-4):83-91. https://doi.org/10.1016/j.hazards.2004.05.002

[25] Mu JE , Chen Y (2016) Impacts of large natural disasters on regional income. Natural Hazards. https://doi.org/10.1007/s11069-016-2372-3

[26] Mell WEM, S.L.; Maranghides, A.; Butry, D.; Rehm, R.G. (2010) The WildlandUrban Interface Fire Problem - Current Approaches and Research Needs. Int J Wildland Fire 19:238-251.

[27] NIST (2015) Community Resilience Planning Guide for Buildings and Infrastructure Systems. Vol. 1 \& 2. https://doi.org/10.6028/NIST.SP.1190v2

[28] Gilbert SW, Butry DT, Helgeson JF, Chapman RE (2015) Community Resilience Economic Planning Guide for Buildings and Infrastructure Systems. https://doi.org/10.6028/nist.Sp.1197

[29] Berck PG, E.; Smith, B.; Barnhart, J.; Dabalen, A. (1996) Dynamic Revenue Analysis for California. (Sacramento, CA). 